\title{
Brazilian Spotted Fever: the importance of dermatological signs for early diagnosis*
}

\author{
Daíne Vargas Couto ${ }^{1}$ \\ Gunter Hans Filho ${ }^{1}$ \\ Aline Blanco Barbosa ${ }^{2}$
}

\author{
Marcelo Zanolli Medeiros ${ }^{1}$ \\ Alexandre Moretti de Lima ${ }^{1}$ \\ Carolina Faria Santos Vicari ${ }^{1,2}$
}

\begin{abstract}
Brazilian spotted fever is an acute febrile infectious disease caused by Rickettsia rickettsii, transmitted by tick bite. As this disease is rare and has high mortality rates in Brazil, the clinical aspects and epidemiological data may help the diagnosis. We report a case of Brazilian spotted fever in a 19-year-old patient who presented maculopapular exanthema in the palmar region and upper limbs, lymphadenopathy, fever, chills, headache, conjunctival hyperemia, nausea, vomiting, dyspnea, myalgia, developing neurological signs and abdominal pain. He was treated with doxycycline with clinical improvement. We emphasize the importance of the recognition of this disease by dermatologists as cutaneous manifestations are the key findings to establish early diagnosis and prevent complications.
\end{abstract}

Keywords: Rickettsia infections; Rickettsia rickettsii; Rocky Mountain Spotted Fever; Skin diseases, infectious

\section{INTRODUCTION}

Brazilian spotted fever (BSF) is a rickettsiosis which manifests itself as an acute febrile infectious disease, of variable severity, from mild and atypical to severe forms. It is characterized by an abrupt onset, with nonspecific signs followed by maculopapular exanthema. ${ }^{1,2}$ Early treatment is essential to avoid more severe forms of the disease. ${ }^{1-5}$ In Brazil, mortality rates are high, between 20 and $30 \%$. This report aims at emphasizing the difficulty in establishing this diagnosis, besides delaying therapeutics, related mainly to nonspecific symptomatology and to little knowledge about the disease. ${ }^{1,6}$ We describe the case of a patient with a late diagnosis who presented characteristic lesions and evolved with systemic symptoms.

\section{CASE REPORT}

Male patient, 19 years old, originally from Dois Irmãos do Buriti-MS, complaining about headache, myalgia, chills, nausea, vomiting and dyspnea. At the examination he presented fever, conjunctival hyperemia, lymphadenopathy, meningeal signs, maculopapular exanthema and purpura on upper limbs and trunk, receiving treatment for viral meningitis with clinical improvement (Figures 1,2 and 3). After one week he evolved with decreasing strength in upper limbs, persistence of fever and regression of skin lesions. At the admission he presented fever, tachycardia, abdomen painful to palpation of left hypochondrium, interosseous atrophy, pain on palpation of muscles of the upper limbs. At the neurological examination he presented balance, proprioception and normal coordination, strength grade IV normal tonus, disproportionately decreased reflexes, hyposensitivity in the forehead region, negative Lasègue, and positive Brudzinsky and Kernig, bilateral dysmetria in finger-to-nose test. An extensive laboratory and imaging research was performed, which showed slight reduction of potassium and albumin, AST 115, ESR of $78 \mathrm{~mm} / \mathrm{h}$ and CRP $19 \mathrm{mg} / \mathrm{dl}$. Liquor analysis revealed pleocytosis at the expense of lymphocytes. Cultures and rheumatologic tests were normal. Echocardiogram revealed mild pericarditis. Serology for syphilis, HIV, hepatitis, cytomegalovirus, dengue fever, toxoplasmosis, leptospirosis, Lyme disease and

Received on 24.08.2013.

Approved by the Advisory Board and accepted for publication on 11.11.2013.

* Work performed at Serviço de Dermatologia Dr. Gunter Hans/Hospital Universitário da Universidade Federal de Mato Grosso do Sul (UFMS) - Campo Grande (MS), Brazil.

Conflict of interest: None

Financial funding: None

Universidade Federal de Mato Grosso do Sul (UFMS) - Campo Grande (MS), Brazil.

Hospital São Julião - Campo Grande (MS), Brazil. 


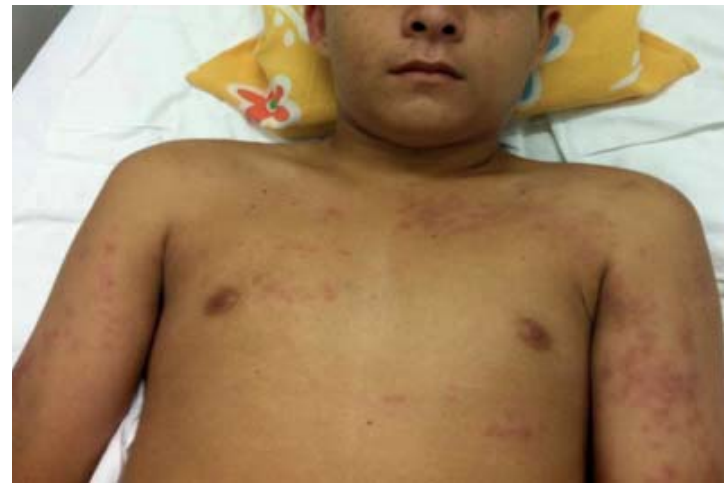

FIGURE 1: Maculopapular exanthema and purpura in trunk and upper limbs

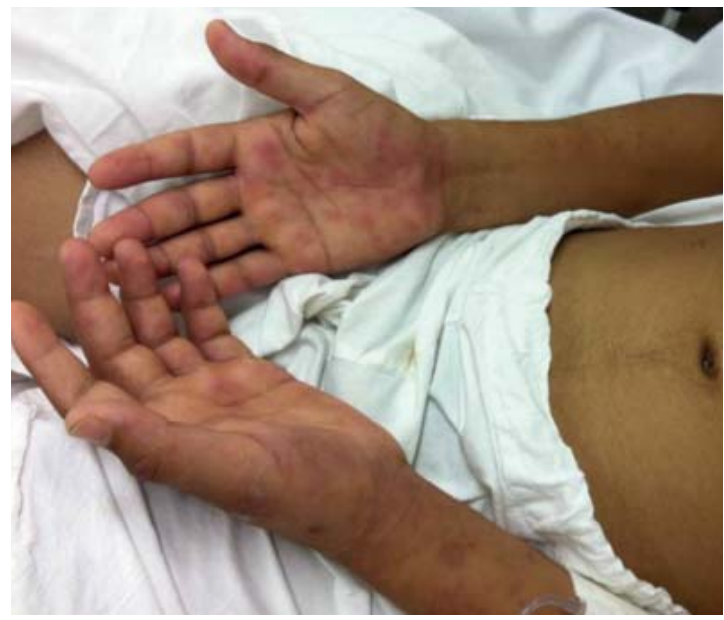

FIGURE 2: Maculopapular exanthema and purpura in palms

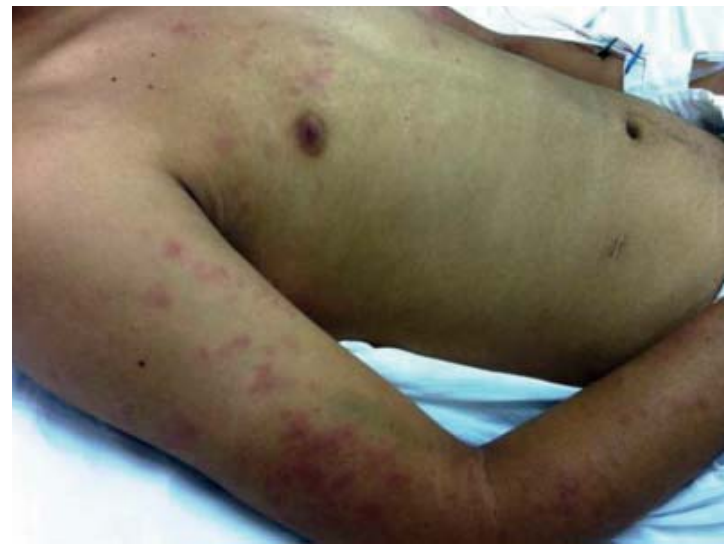

FIGURE 3: Maculopapular exanthema and purpura in arms rubella were negative. Indirect immunofluorescence for spotted fever was performed with a titer of $1 / 128$ and the second, held 15 days after the first, of 1/256. He was treated with doxycycline 200 mg every 12 hours for 30 days with good resolution.

\section{DISCUSSION}

BSF is an emerging disease of compulsory notification caused by the Rickettsia rickettsiis, having ticks as its main transmission vector, especially the Amblyomma cajennense. Currently, the state of Mato Grosso do Sul is not an endemic area. From 2007 to 2013 only two cases were notified, probably denoting sub-notification. ${ }^{7}$ Capybaras and equidae are the main hosts of ticks. ${ }^{1,2}$ The transmission occurs through tick bite and the incubation period is variable, from 2 to 14 days, with an average of 7 days. ${ }^{1,2}$

Initially symptoms are nonspecific such as high fever, headache, myalgias, malaise and conjunctival hyperemia. ${ }^{1,2,4,58}$ Gastrointestinal symptoms such as vomiting, diarrhea, abdominal pain and hepatomegaly may also occur. ${ }^{1,2,6}$

Maculopapular exanthema is the main sign to define the diagnosis. ${ }^{1,2,3}$ It appears in few patients on the $1^{\text {st }}$ day of the disease and is present in about $49 \%$ of the sick until the $3^{\text {rd }}$ day and in $91 \%$ by the $5^{\text {th }}$ day. The absence of this manifestation may occur in 9 to $12 \%$ of the infected, specially the elderly and darkskinned people, making the diagnosis difficult. The macules have centripetal evolution with rosy aspect, with poorly defined edges, measuring from 2 to $6 \mathrm{~mm}$ in diameter. They usually appear around wrists and ankles, and can also appear in the thoracic region. Palmoplantar exanthema occurs in 40 to $80 \%$ of patients and it is considered a characteristic sign of the disease. Initially the macules disappear under digital pressure. In severe cases, the exanthema changes into petechiae and later becomes hemorrhagic, composed mainly of ecchymoses or suffusions. ${ }^{2}$ There may also occur tissue necrosis, gangrene and ulcer. ${ }^{1,2,9}$ The retardation in the appearance of these lesions determines delay in diagnosis and worsening of prognosis.

With the absence of treatment and progression of the picture, there can be involvement of the central nervous system. The presence of the microorganism in blood vessels of meninges and brain causes pleocytosis in 35\% of the patients. ${ }^{1,2}$ Renal involvement indicates severe prognosis. ${ }^{1,2}$ Pulmonary and hemorrhagic manifestations may occur. ${ }^{2}$

Anemia and thrombocytopenia are common. Leucocytes may be normal, enlarged or diminished. Creatine kinase, lactate dehydrogenase, aminotransferases and bilirubin levels are usually increased. ${ }^{1,2,4}$

Several diseases pair with BSF for differential diagnosis such as leptospirosis, dengue, viral hepati- 
tis, salmonella, encephalitis, malaria, pneumonia by Mycoplasma pneumoniae, meningococcemia, sepsis, exanthematic disease, typhus, ehrlichiosis, borreliosis, pharmacodermia and rheumatic diseases. ${ }^{1,2,4,8,10}$ Diagnosis can be done through serological tests, direct research and molecular biology techniques. ${ }^{1,2,3,4,5,8}$

The immunofluorescence reaction is the gold standard, with high sensitivity and specificity. Antibodies are detected between the $7^{\text {th }}$ and $10^{\text {th }}$ day of the disease..$^{1,23,4,5,8}$ Greater or equal titers than 1:64 in a single sample or four-fold titer increase, observed in two paired serum samples, collected 2 to 4 weeks apart, confirm the diagnosis. ${ }^{1,2}$ Class IgG antibodies are more specific. ${ }^{2}$

In samples obtained through biopsy of skin lesions or necropsy material from lesioned organs direct research of rickettsiacan be done through histopathology/immunohistochemistry. ${ }^{1,2}$

In fatal cases, with death in the first 7 days, and when there is need of confirmation without the possibility of a second serum sample, molecular biology techniques (MBT) can be used..$^{1-5,8}$
Tetracyclines and chloramphenicol are the only drugs with proven action and efficacy. In adults, doxycycline must be administered in two daily doses of $100 \mathrm{mg}$ during 7 days or for 2 more days after remission of fever. ${ }^{1,2}$

In our case, in spite of positive epidemiology and characteristic manifestations, such as maculopapular exanthema in the palmoplantar region, unspecific symptoms associated with scarce knowledge of the disease led to a delay in the diagnosis and the patient evolved to systemic involvement. After serological confirmation, he presented a significant improvement with the use of doxycycline. We emphasize the importance of knowledge of this disease by dermatologists, including it in differential diagnosis of acute febrile diseases, valuing the peculiar exanthema that it usually develops.

\section{REFERENCES}

1. Fiol FSD, Junqueira FM, Rocha MCP, Toledo MI, Barberato Filho S. A febremaculosa no Brasil. Rev Panam Salud Publica. 2010;27:461-6.

2. Fundação Nacional de Saúde. Guia de vigilância epidemiológica. 5 ed. Brasília: Funasa, 2002. 842p.

3. Favacho AR, Rozental T, Calic SB, Scofield MA, Lemos ER. Fatal Brazilian spotless fever caused by Rickettsia rickettsii in a dark-skinned patient. Rev Soc Bras Med Trop. 2011;44:395-6.

4. de Lemos ER, Rozental T, Villela CL. Brazilian spotted fever: description of a fatal clinical case in the State of Rio de Janeiro. Rev Soc Bras Med Trop. 2002;35:523-5.

5. Amâncio FF, Amorim VD, Chamone TL, Brito MG, Calic SB, Leite AC, et al. Epidemiological characteristics of Brazilian spotted fever in Minas Gerais State, Brazil, 2000-2008. Cad Saude Publica. 2011;27:1969-76.

6. Spolidorio MG, Labruna MB, Mantovani E, Brandao PE, Richtzenhain LJ, Yoshinari NH. Novel Spotted Fever Group Rickettsiosis, Brazil. Emerg Infect Dis. 2010;16:521-3.

7. Saúde.gov.br [Internet] Prevalência da febre maculosa no Estado de Mato Grosso do Sul, 2007-2013. [acesso 17 out 2013]. Disponível em: http://dtr2004.saude.gov.br/sinanweb/index.php

8. Seijo A, Picollo M, Nicholson W, Paddock C. [Rickettsial spotted fever in the Paraná Delta. An emerging disease]. Medicina (B. Aires). 2007;67:723-6.
9. Silva N, Eremeeva ME, Rozental T, Ribeiro GS, Paddock CD, Ramos EA, et al. Eschar-associated spotted fever rickettsiosis, Bahia, Brazil. Emerg Infect Dis. 2011;17:275-8

10. Fonseca AH, Salles RS, Salles SAN, Madureira RC, Yoshinari NH. Lyme borreliosis simile: an emergent and relevant disease to dermatology in Brazil. An Bras Dermatol. 2005;80:171-8.

\author{
MAILING ADDRESS: \\ Daine Vargas Couto \\ Av. Senador Filinto Muller, 355 \\ Vila Ipiranga \\ 79080190 - Campo Grande - MS \\ Brazil \\ E-mail: dainevargas@yahoo.com.br
}

How to cite this article: Couto DV, Medeiros MZ, Hans-Filho G, Lima AM, Barbosa AB, Vicari CFS. Brazilian Spotted fever: the importance of dermatological signs for early diagnosis. An Bras Dermatol. 2015;90(2):248-50. 